\title{
Weapons and Explosives Information Tracking and Alerting System: A Real-Time Approach
}

\author{
Moses O. Onyesolu ${ }^{1}$, Macdonald N. Onyeizu ${ }^{2}$, Celestine. O. Uwa ${ }^{3}$, Charles. O. Ugwunna ${ }^{4}$ \\ Senior Lecturer, Computer Science Department, Nnamdi Azikiwe University, Awka, Nigeria ${ }^{1}$ \\ P. G. Student, Computer Science Department, Nnamdi Azikiwe University, Awka, Nigeria ${ }^{2,3,4}$
}

\begin{abstract}
One of the teething concerns of government is the security of the citizens of the country. It is no news to say that individuals who do not have licenses gain access to ammunition and weapons. Suffice to say that inadequacy in the management of weapons especially those kept in the stockpiles has been identified as a major contributing factor. Poor stockpile management of weapons results in the deterioration of ammunition leading to an unsafe environment for citizenries. Conversely, the safe, efficient, and effective management of national stockpiles of conventional ammunition and explosives would enhance military and police capabilities and also reduce threat and fear of unwanted explosions. The main idea of this work is to study the national weapon and ammunition stockpiles and develop an effective system with real-time features to enable countries have effective mechanism to keep track of their weapons, ensuring safe storage and reduce risks of illegal theft of weapons and identifying losses quickly. This work will serve as an effective element for counter-proliferation and ensuring the safety of explosives. The real-time feature of the system will help in identifying weapons and explosives that require maintenance. However, pre-information on weapons and ammunition expiry date and shelf-life will be notified by the system. Finally, legal weapons recovered from crime scene would be run an instant check to know the personnel officially assigned to it/them.
\end{abstract}

Keywords: Ammunitions, Armoury, Explosives, Personnel, Real-time, Shelf-life.

\section{INTRODUCTION}

Security challenges in the world have posed serious threats injured and some properties damaged. Meanwhile, two to smooth governance and economic development of similar incidences were recorded in North Korea in affected nations. At one point or another, some countries February 2004 and April 2004; where total of one are held at ransom following one form of security thousand and fifty four (1054) innocent lives were lost, challenge or the other. The dangerous dimension is that the many injured and so many properties lost.

security challenge has become a great source of worry as security experts affirm that what is on ground has shifted to the realm of terrorism and kidnapping, global phenomena where no one is safe (Bosun, 2012). This has amounted to destruction of property, sending innocents citizens to their early grave and all that.

However, some countries face internal security challenges as security agents illegally lease guns or ammunitions to robbers, touts and terrorists to perpetuate crime. (Bisola, 2012) pointed out that there have been good number of criminals arrested at one time or the other with different security uniforms and weapons that were acquired by security agencies and officially assigned to security personnel. Another serious problem facing security agency is improper storage of ammunition and explosives. A survey by Wilkinson (2005) found out that between 1997 and 2005, there were ninety three (93) known or suspected explosive events at ammunition storage areas which led to destruction of property, death of citizens and injury to many. From the survey, Nigeria led in the casualty list while North Korea follows. In January 27, 2002, over one thousand five hundred $(1,500+)$ innocent lives were lost, many sustained injuries and properties damaged as a result of expired explosives triggered off from the Army Armoury at Ikeja Cantonment, Nigeria. In a similar a. incident that happened in Kaduna, Nigeria on February 23, of ammunitions, ballistic finger printing can equally be 2005, about five (5) innocent lives were lost with many

The above mentioned challenges and problems have been easier and possible because there have been insufficient tracking system for legally acquired weapons and ammunitions and real-time feature to detect or identify weapons' shelf-life, maintenance period as well as expiry date. Hence, the need to develop a system to tackle the above problems becomes paramount. Therefore, this work is aimed at curbing the excesses of our security agents by tracking weapons officially assigned to them and preventing self detonation of explosives devices as a result of inadequate maitenance. The objectives of this work are:

a) To identify security personnel in possession of weapons at any given time.

b) To identify who was assigned any weapon recovered from crime scene.

c) To identify the shelf life, maintenance and/or expiry periods for explosive weapons.

d) To identify a range of time in months to the expiration date, shelf life and maintenance date which will serve as early warning guide or information to avoid catastrophe (self-detonation).

\section{Some Methods of Tracking Weapons}

Tracking Weapons using Forensics: In tracking
unitions, ballistic finger printing can equally be employed. According to Kopel (2008), ballistic finger 
printing refers to a set of forensic techniques that rely on number of boxes and the manufacturers of specific marks that firearms leave on bullets to match a bullet to weapons that are being given to a particular unit. the gun it was fired with. In addition to recording the Individual records are not being kept especially on markings from guns used in crimes, the system is designed ammunitions dissemination and use.

to record markings from the test firing of every new gun. If

the database does eventually contain the majority of Since the Defense Headquarters allocates weapons of a firearms manufactured, it would be possible for the police particular type and make to a given unit at any point in to start the trace process with nothing more than a bullet or time, it makes it easy for them to identify any weapon a casing left at a crime scene. He stated further that it is a intercepted anywhere as having come from a particular subset of forensic ballistics (the application of ballistics to area.

legal questions) and internal ballistics (the study of events

between the firing of a gun and the bullet leaving the But in a situation where as a result of crises in a particular barrel).

b. Ballistic Fingerprinting Techniques and Aids: area, security agencies are brought in from other areas to assist in calming down the situation and since the incoming contingent must come with their weapons, one Karen (2008) identified ballistic fingerprinting techniques as based on the principle that all firearms have inevitable variations due to marks left by the machining process, leaving shallow impressions in the metal which are rarely completely polished out. Also, normal wear and tear from use can cause each firearm to acquire distinct characteristics over time.

c. Missile Guidance: Missile guidance refers to a variety of methods of guiding a missile or a guided bomb to its intended target. The missile's target accuracy is a critical factor for its effectiveness. Guidance systems improve missile accuracy by improving its "Single Shot Kill Probability" (SSKP), which is part of combat survivability calculations associated with the salvo combat model. These guidance technologies can generally be divided up into a number of categories, with the broadest categories being "active," "passive" and "preset" guidance. Missiles and guided bombs generally use similar types of guidance system, the difference between the two being that missiles are powered by an onboard engine, whereas guided bombs rely on the speed and height of the launch aircraft for propulsion [6].

\section{III.PRESENT SYSTEM OF TRACKING WEAPONS}

The Defence Headquarters is the only sole authority charged with the responsibility of the acquisition and distribution of weapons of any type to the country's armed forces. These weapons could be imported into the country from other countries especially those countries in which the country has an arms treaty deal with. When these weapons are brought into the country, they are taken to the National Armoury for storage. It is from the National Armoury that distribution of weapons are effected to Divisions and other units under the Divisions according to demand. Each Division has a Central Armoury where weapons coming from the Defence Headquarters are kept and from there units are identified and allocated to according to their need.

expects non-uniform weapons to be seen and used in that area. Irrespective of this mixture of weapons, the authorities have comprehensive record of the types and makes of weapons given to each unit in the country. Therefore, any weapon used in such area can be traced back to where it is coming from (George, 2005). These tracking and tracing system of weapons is done manually and it is prone to errors.

\section{IV.STORAGE OF WEAPONS}

Weapons are stored in the Armoury, (a place where weapons and military equipment are kept). Weapons may deteriote or become damaged unless it is correctly stored, handled, and transported. As a result, it may fail to function as designed and become dangerous in storage, handling, transit and use. Armories are built underground and always air-conditioned. The air-conditioning system is put in place to control the temperature of the Armoury. The authorities always make sure that there is constant power supply to run the air-conditioners and that the air conditioners are in good working condition. The environmental requirements (temperature, humidity, and vibration) of weapons vary, and are dependent on their intended storage conditions (including shelf life), transportation, handling, and use. The performance of explosives will be unpredictable and their safety will be reduced if the manufacturers' environmental conditions are not met while in long-term storage. Some substances used in weapons attract and hold moisture, which may result in the degradation of explosive performance. It may also cause them to become dangerous to handle because of the potential for the formation of sensitive explosive crystals between the fuse and main body of the weapons. Rain, dampness, and humidity can cause enormous damage to weapons in a short time. This is very important for the weapons to work properly and is therefore adequately catered for by the authorities.

The weapons are normally arranged by type, model and make; with the less frequently used and maintained ones always at the rear.

These weapons come in boxes and each box contains The following materials are restricted to be taken close to certain number of firearms and ammunitions. The the armoury: matches, lighter, candles, fire-works, boots authorities are only much interested in knowing the 
having cracker underneath, smoking of cigarette, and log card equally carries the same butt number as the generally anything that can ignite fire.

\section{MAINTENANCE OF WEAPONS} weapon. The other information in the log card are the type, make and model of weapon, personnel name, service number, date, time of signing in and signing out the weapon and a column for remarks by the gunnery officer.

Weapons that need to be maintained always have the accompanying maintenance period and procedure state by the manufacturer. Every weapon that is regularly used is always checked and maintenance carried out on it on a weekly basis. Those categories of weapons that are rarely used are checked and maintained on a quarterly or yearly basis.

Explosive devices by the terms of their manufacture are supposed to be taken back to the manufacturer on a regular interval of 6 to 12 months for renewal. This renewal, at times is ignored, generally, because of negligence of duty. Maintenance is often ignored, with inevitable costly consequences. There are many horror stories about otherwise excellent weapons that have no maintenance culture. Also, the shelf life of weapons (the length of time an item of weapon may be stored before its performance degrades) is a very important element in maintenance that is often ignored.

\section{WEAPONS ALLOCATION AND CONTROL STRATEGIES}

Uwa (2015) opined that every country's Armoury has an overall boss called the armourer, who is responsible for the safe keeping and general administration of weapons in the Armoury. Next to the armourer is the gunnery officer who issues weapons to personnel/officers for whatever official assignment they are engaged in and receives them back after such assignments. For instance, the Nigerian Army and indeed other security agencies have their peculiar means of identifying and controlling weapons. In the Nigerian Army, every weapon has its unique identity called a Butt number. This Butt number is of the from MPA/012, where MPA is the unit of the Army having that particular weapon and 012 is the serial number of the weapon and is always written on the body of the firearm with any coloured paint. The serial number used here is specific to any given unit and has no relationship with the manufacturer's serial number.

Every army personnel in any given unit has a particular weapon allocated to him/her as long as that personnel is attached to that unit. That is to say that each personnel can identify his/her own weapon by using his/her assigned butt number. Once a personnel is posted out of any given unit, his/her new unit will give him/her a new butt number specific to a particular weapon. In addition, every personnel has a tally bearing the same butt number as on the weapon. The personnel will keep the tally with him/her until the weapon is needed. Whenever a personnel goes to the Armoury to sign a weapon, such personnel presents the tally to the gunnery officer who uses the presented tally to identify such personnel's weapon. Once the corresponding weapon is identified, the personnel will then sign the appropriate columns in the accompanying log card. The However, the required entries to be made at the point of collection are the date, time, sign-out and remarks by the gunnery officer. Once this is done, the personnel goes away with the weapon. On returning the weapon, the personal signs in the appropriate columns and then gets back his/her tally.

On the other hand, every ammunition has a serial number engraved on its right from the manufacturer. However, our security agencies pay no particular attention to such serial numbers when issuing them out to personnel on duty or special assignments. As was noted earlier, the ammunition comes in boxes which contain packets of about 1000 rounds or more per packet. The gunnery officer gives each personnel on assignment a particular number of rounds without keeping record of their serial numbers. Hence, nobody can say with certainty who has been given a particular ammunition, although, they can only identify the manufacturer since units get their allocation from a particular manufacturer or vendor. Therefore, any ammunition found in a crime scene cannot be traced to any personnel since records are not being kept except the number of rounds given out.

\section{PROBLEMS OF THE EXISTING SYSTEM}

i) Ammunitions are allocated to personnel without regard to the serial numbers or code numbers and even the type, model and manufacturer. Since such records are not being kept, it is not possible to trace any bullet or shell casing found at a crime scene to the personnel who fired such ammunition.

ii) Firearms are allocated through the use of Butt numbers which actually served for identification and control. However, these numbers are handwritten on the firearms and can easily be erased by any criminal who intends to use it and carry out a crime.

iii) The use of $\log$ cards by gunnery officers to keep record of weapons is manual and is prone to errors and manipulations by corrupt personnel/officers.

iv) The lack of proper record keeping has made it possible for personnel to illegally fire allocated ammunition and source for replacement from different quarters without the gunnery officers noticing it. At times, the sourced replacements are even of different models and makes.

v) The lack of maintenance culture in our system has made it possible for the maintenance of weapons difficult to be carried out on time except when such weapons start malfunctioning. Proper records are not usually kept on how and when to carry out such maintenance activities.

vi) Lack of proper maintenance and monitoring of the armoury. At times the air conditioners that control the temperature of the armoury malfunction and is usually 
noticed late or even ignored thereby posing serious A. Administrator Module

threat to lives and property.

This module could be called amourer module and it

vii) Certain types of explosive devices by the nature of enables the system administrator to configure and maintain their function and terms of agreement during supply various variables in the system such as create users, are expected to be taken back to the manufacturer at manage users, weapon information, personnel information, intervals of say 6 to 12 months for renewal; but this is check period (expiry, maintenance and shelf life dates), often ignored to the detriment of the country at large etc. System user with administrator role is the user with and the immediate environment in particular.

VIII. OUR PROPOSED SOLUTION super user role to the system. This category of user will have the full administrative access rights to each module in the system. The administrator is the "gatekeeper" of the In view of all the problems mentioned above ranging from system and has right to assign users to different role in the storage, allocation to tracking, we proposed a system.

computerised weapon tracking system to enable ministry of defence manage their weapons and ammunitions. The architecture of the system is described below.

\section{IX.HIGH LEVEL MODEL OF THE NEW SYSTEM}

\section{B. User Module}

System users with user role are those users with gunnery role as assigned by the system administrator (amourer). These group of users have limited access or privilege to all The system we developed basically has two modules - components of the system. Some of the privileges given to administrator and user (amoury) modules. However, these this group of users are sign in/out weapons, check modules have sub-modules which are described below:

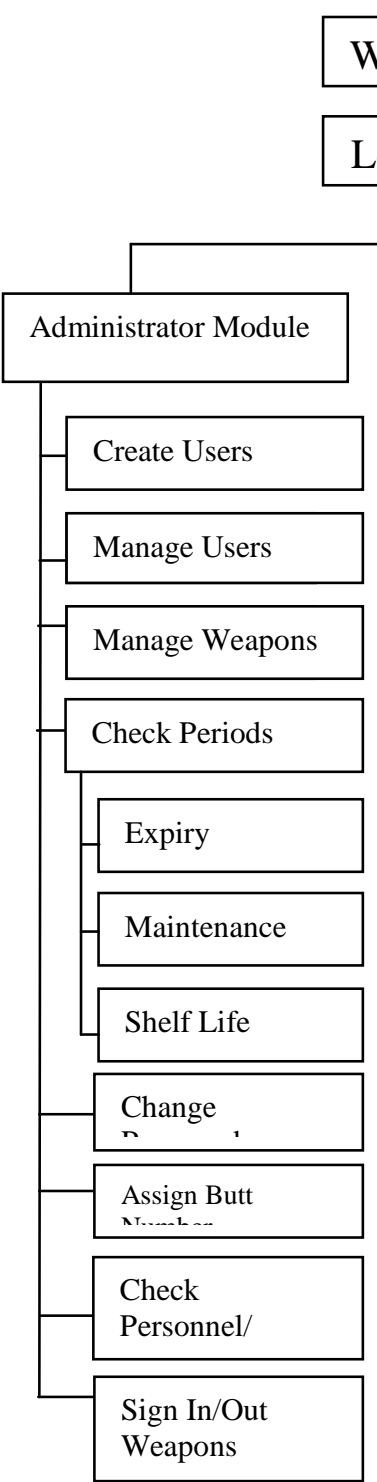
weapons, check periods (expiry, maintenance and shelf life dates), weapon and personnel information, etc. meanwhile the high level model of the system is presented in figure 1.

\section{ADVANTAGES OF THE SYSTEM}

The Weaponry Information and Tracking System only covers weapons legally acquired from known sources and then distributed officially to known security agencies. Serial numbers of weapons with their features are stored in a comprehensive database along with the information of their handlers. When a firearm, spent bullet, spent cartridge case (shell) or live ammunition is recovered at a crime scene, it would easily be traced to the source. Thus, the system would be very useful in tracing weapons used in crimes, the people involved, and their suppliers if such culprits are not security agents. The system has the following unique features:

a) Real-Time Search of weapons expiry date: One important feature of this new system is that expiry dates of weapons are easily detected by the system. A system check is run at a regular basis and the user is expected to enter a period in month(s) in which the system will display any or all weapons due to expire within the stated period in form of a report.

b) Real-Time Search of weapons maintenance period: Another important feature of this new system is that maintenance period of weapons are detected by the system. If the period for maintenance draws close according to the time period in month(s) set by the armourer or whoever is designated to do so, the system displays in report form all weapons due for maintenance at the stated period.

c) Real-time search of weapons' shelf-life: This feature helps the system to detect the shelf-life of weapons. As earlier stated, shelf-life is the length of time weapons may be stored before the performance degrades.

\section{XI.CONCLUSION}

Considering the constant rise in security challenges in the world and the need to reduce them, we have developed this system to help in curtailing some of the problems

Fig. 1. High Level Model of the New System 
experienced by the security agencies. This system is installable in both mobile and desktop devices. This will enable security agencies to keep track of their weapons and personnel in possession of those weapons. The system is embedded with real-time alert feature. This feature will alert the user on the weapons that are about to expire, those that require maintenance and those that are about to degrade. This will go a long way in eradicating the problems facing the security agencies on weapon and ammunition management.

\section{REFERENCES}

[1] A. Bosun, Security challenges pose risk to Nigeria. Coastweek Newspapers Ltd. December 21, 2012.

[2] B. O. Bisola, Issues of Insecurity: How complicit are the security agencies - A comprehensive resolution of Nigeria's security issues. Vanguard Newspaper, June 27, 2012.

[3] C. O. Uwa, Design and Implementation of Weaponry information and Tracking system: For Nigerian army. Unpublished Thesis submitted to the Department of Computer Science, Nnamdi Azikiwe University, Awka, 2015.

[4] A. Wilkinson, Targeting Ammunition - Stockpile Management of Ammunition. Chapter 8, Pages 248 - 252, 2005

[5] D. B. Kopel, Ballistic fingerprints. In Ayn Embar-seddon, Allan D. Pass (eds.). Forensic Science. Salem Press. 2008

[6] L. Karen, "Foressic Ballistics", 2008.

[7] K. Carlo, Active and Semiactive Radar Missile Guidance. Australian Aviation, 2005, 1982. Available: http://www.ausairpower.net/TE-Radar-AAMs.html, http://en.wikipedia.org/wiki/Missile_guidance 